\title{
FAILURE OF STENT DELIVERY IN LIMA PCI
}

\author{
Rama Krishna Janapati, G Shanthi Sneha, Indrani Garre
}

\section{ABSTRACT:}

Back Ground: The internal mammary artery was the most effective conduit for coronary artery bypass surgery and it was associated with significantly better long term patency, survival, and reintervention rates compared to other bypass conduits. The internal mammary artery (IMA) is not immune to atherosclerosis. IMA interventions constitute low percentage out of all coronary interventions. In addition to the tortuous course, the long length of IMA than native coronaries adds procedural difficulties to IMA PCI.

Aim: To analyze the acute outcomes of Percutaneous intervention procedures to the internal mammary artery and to found any association with clinical and demographic parameters to the procedural success at a single tertiary care hospital from India

Materials And Methods: This study was a retrospective analysis of post CABG patient who required and undergone the IMA intervention. We collected the clinical, demographic and procedural details of the IMA intervention. We defined as failure of the procedure when the stent could not be delivered to the lesion site through IMA.

Results: Total 21 patients were included in this retrospective

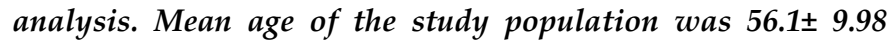
years and 18 patients were male. Twelve (57.1\%) patients presented with chronic stable angina and six (28.6\%) had Left ventricular dysfunction (LVD) (mild LVD in 5 and one patient had severe LVD). Mean stent diameter was $2.75 \pm 0.442 \mathrm{~mm}$ and the mean stent length was $17.71 \pm 5.63 \mathrm{~mm}$. Transient slow flow occurred in 5 patients, but the end result of PCI procedure was good in them. In 4 (19.1\%) patients stent could not be delivered. No LIMA dissections were observed. On binary logistic regression, there was no significant difference between successful PCI to the failed PCI with respect to age ( $p=0.9$, $z=0.16, O R=0.99,95 \% C I=0.83$ to1.17), male sex $(p=0.7, Z=0.34$, OR=1.68), type of presentation $(p=0.7, Z=0.38, O R=1.60$, $95 \% \mathrm{CI}=0.14$ to 17.7$)$, presence of Left ventricular dysfunction $(p=0.7, z=0.38, O R=1.60,95 \% C I=0.14$ to 16.97$)$ and with predilatation during PCI ( $p=0.9, z=-0.16, O R=0.99)$.

Conclusion: PCI to the internal mammary artery was associated with $80.95 \%$ of success. Not able to deliver the stent to the target lesion was the major problem with LIMA PCI, in addition, to slow or no flow. The success or failure of

Article received on 01 JAN 2017, published on 31JAN 2017.

Rama Krishna Janapati ${ }^{1}$, G. Shanthi Sneha ${ }^{2}$,Indrani Garre ${ }^{3}$

${ }^{1}$ Senior Resident, Department of Cardiology, NIMS, India

2 Senior Resident, ESI, India

${ }^{3}$ PhD Student, Department of Cardiology, NIMS, India

Corresponding author: Rama Krishna Janapati

Email: dr.rkyadav400@gmail.com
PCI were not dependent on the age, sex, type of presentation or LV dysfunction.

Keywords: Coronary Artery Bypass Graft, Conduits, Internal Mammary Artery, Bypass graft PCI.

\section{INTRODUCTION:}

The internal mammary artery (IMA) graft was the preferred conduit for coronary artery bypass grafting $(\mathrm{CABG})$ because of the long term patency rate and lower prevalence of restenosis when compared to Saphenous venous grafts (SVG).Unlike saphenous vein grafts, IMAs rarely develop arteriosclerosis [1].Unadjusted 1, 5, and 10 -year patency was $93 \%, 88 \%$, and $90 \%$ for internal mammary arteries and $78 \%, 65 \%$, and $57 \%$ for saphenous veins. At 10 years, internal mammary arteries were more likely than saphenous veins to be patent to left anterior descending in $99.1 \%$ of cases, to diagonals in $98.3 \%$, to circumflex in $98.3 \%$, to a posterior descending artery in $98.5 \%$, and to right coronary arteries in $82.5 \%$. However, by 10 years, internal thoracic artery patency was better in right coronary arteries with $70 \%$ stenosis or greater [2].A disadvantage of the arterial grafts was their susceptibility to spasm and early occlusion when used to CABG with only moderate proximal stenosis with the competitive flow in the native vessel [3].However, some patients develop stenosis of IMA grafts due to intrinsic atherosclerotic disease, distal anastomosis site stenosis or damage during the harvesting procedure. LIMA graft lesions are most commonly located at the distal anastomosis site, followed by the graft body [4,5]. Loss of patency of Internal mammary artery was associated adverse consequences and there were limited published case reports of PCI to stenosed internal thoracic artery. In this study, we retrospectively reviewed the immediate outcomes of PCI procedure to the internal mammary artery and the technical difficulties at a single tertiary care hospital from India.

\section{MATERIALS AND METHODS:}

We retrospectively analyzed the data of the post CABG patients who underwent Percutaneous revascularization to LAD/Diagonal and LIMA through the left internal mammary artery between the year 2010 to 2015 from a single center in south India by different operators. We collected the clinical, demographic and procedural details of the LIMA intervention. The femoral artery was 
the access site in all the patients and Judkins right (JR $6 \mathrm{~F}$ ) or LIMA guide catheter was used. At the beginning of the procedure, all patients were given weightadjusted heparin intravenously. Predilatation of the lesion was done whenever is required. All patients received dual antiplatelet drugs and high dose statin before PCI and continued after the procedure. Procedural failure was defined as when stent could not be delivered to the lesion site through LIMA due to various reasons. Angiographic success was defined as a minimum stenosis diameter reduction to less than $20 \%$ after the PCI. Procedural success was defined as angiographic success without major clinical complications (e.g., death, MI, emergency CABG) during hospitalization. Binary logistic regression was used to analyze the results.

\section{RESULTS:}

The present study included total 21 patients who underwent Percutaneous revascularization to stenosed left internal mammary artery or native coronary artery which was grafted between years 2010 to 2015 by different operators from a single center in south India. This study was a retrospective analysis of post CABG patients who undergone the PCI through LIMA. Basal demographic and clinical characters of all 21 patients were summarized in Table 1.

Table 1: Baseline characters of the patients

\begin{tabular}{|c|c|c|c|c|}
\hline S.No & $\begin{array}{l}\text { Age/ } \\
\text { gender }\end{array}$ & $\begin{array}{l}\text { Clinical } \\
\text { symptom }\end{array}$ & $\begin{array}{l}\mathrm{LV} \\
\text { function }\end{array}$ & Stent /length \\
\hline 1 & $70 / \mathrm{M}$ & CSA & Good & $\mathrm{DES} / 2.25 \times 18$ \\
\hline 2 & $66 / \mathrm{M}$ & CSA & Good & DES $3 \times 18$ \\
\hline 3 & $46 / \mathrm{M}$ & CSA & Good & DES2.5×13 \\
\hline 4 & $51 / \mathrm{M}$ & CSA & Mild & DES2.5×12 \\
\hline 5 & $40 / \mathrm{M}$ & CSA & Good & POBA \\
\hline 6 & $58 / \mathrm{M}$ & USA & Good & DES2.75×15 \\
\hline 7 & $48 / \mathrm{M}$ & USA & Mild & DES $2.5 \times 13$ \\
\hline 8 & $57 / \mathrm{M}$ & STEMI & Good & DES2.5×32 \\
\hline 9 & $65 / \mathrm{M}$ & CSA & Mild & Not crossed \\
\hline 10 & $57 / \mathrm{M}$ & CSA & Good & DES2.5×12 \\
\hline 11 & $70 / \mathrm{M}$ & ACS & Good & DES2.75×13 \\
\hline 12 & $68 / \mathrm{F}$ & CSA & Good & DES3×18 \\
\hline 13 & $63 / \mathrm{F}$ & ACS & Mild & POBA \\
\hline 14 & $59 / \mathrm{M}$ & ACS & Good & POBA \\
\hline 15 & $51 / \mathrm{M}$ & ACS & Severe & DES3×24 \\
\hline 16 & $57 / \mathrm{M}$ & CSA & Good & DES $2.5 \times 18$ \\
\hline 17 & $56 / \mathrm{M}$ & CSA & Good & DES $2.5 \times 24$ \\
\hline 18 & $58 / \mathrm{M}$ & CSA & Good & DES2.5×22 \\
\hline 19 & $57 / \mathrm{F}$ & CSA & Mild & BMS $3 \times 19$ \\
\hline 20 & $59 / \mathrm{M}$ & ACS & Good & DES2.75×14 \\
\hline 21 & $53 / \mathrm{M}$ & ACS & Good & BMS $2.5 \times 16$ \\
\hline
\end{tabular}

The mean age of the study population was $56.1 \pm 9.98$ years, 18 were male and $12(57.1 \%)$ of patients presented with chronic stable angina. Six (28.6\%) patients had LV dysfunction (mild LVD in 5 and one patient had severe LVD). LIMA was given to Left anterior descending artery (LAD) in 20 patients and in one patient LIMA was anastomosed to Diagonal artery. Femoral artery was the access site in all the patients and Judkins right (JR 6F) guide catheter was used in 15 patients and LIMA guide catheter was used in 6 patients. Distal anastomosis site was narrowed in $81 \%$ patients. Predilatation was done in 18 patients. Drug eluting stents were used in 15 patients and bare metal stents were used in two patients. Mean stent diameter was $2.75 \pm 0.442 \mathrm{~mm}$ and the mean stent length was $17.71 \pm 5.63 \mathrm{~mm}$. Transient slow flow occurred in 5 patients, but at the end of the procedure, all these five patients had TIMI III flow in the distal target vessel. Angiographic Success was achieved in $80.9 \%$ with reduction of the mean luminal stenosis to less than $20 \%$ and in $4(19.1 \%)$ patient's stent could not be delivered. In this study, we were able to cross the lesion with wire in $95.2 \%$ of the cases and in one case even wire was also not able to cross the target lesion site due to total occlusion at the anastomotic site. Conventional balloon angioplasty was used in three patients successfully. No deaths or emergency CABGs were associated with the procedure and there was no major flow limiting LIMA dissections.

Fig1: Box Plot of age with failed or successful of PCI

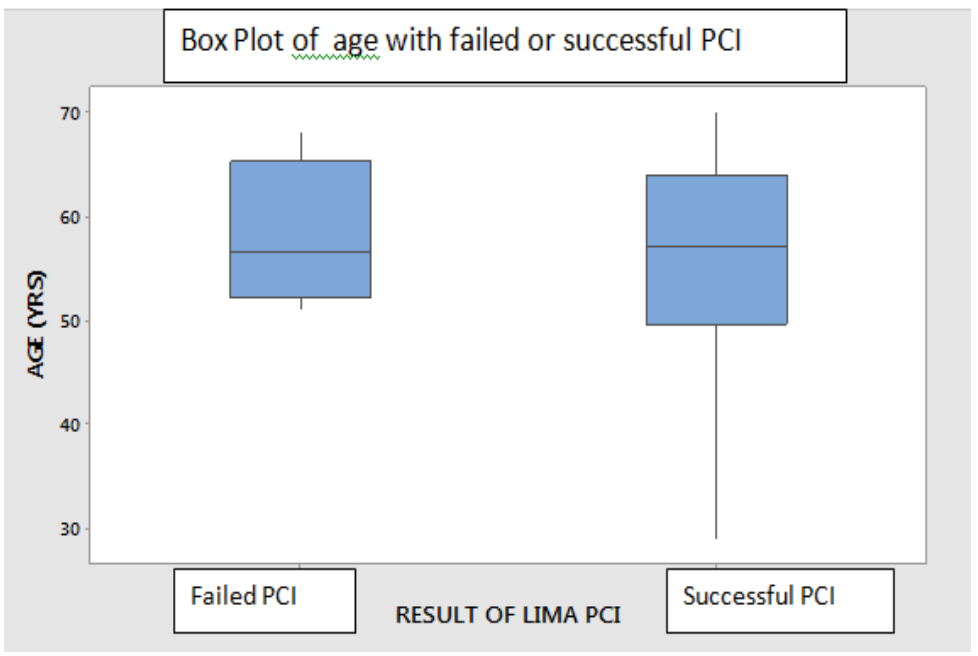


Fig 2: Clinical Variables in success or failed LIMA PCI

\section{CLINICAL VARIABLES IN SUCESS OR FAILED LIMA PCI}

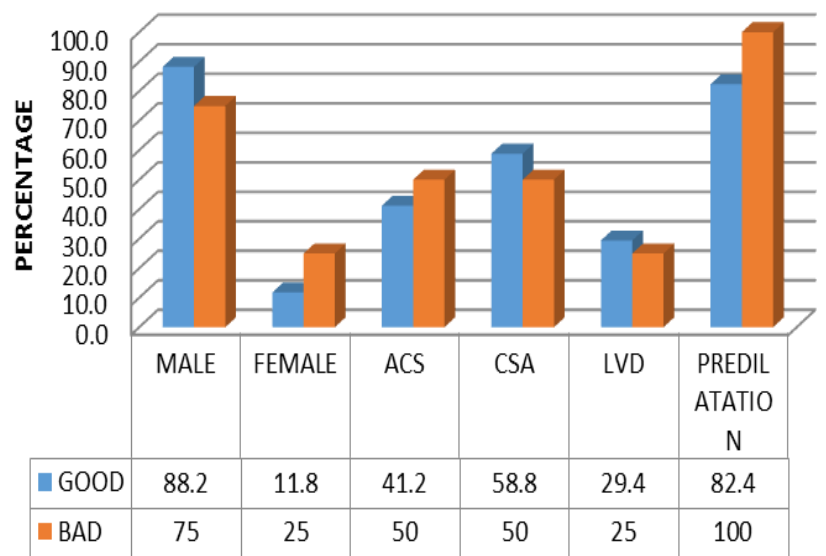

On binary logistic regression, there was no significant difference between successful PCI to the failed PCI with respect to age ( $\mathrm{p}=0.9, \mathrm{z}=0.16, \mathrm{OR}=0.99,95 \% \mathrm{CI}=0.83$ to 1.17) (Fig.1), male sex ( $p=0.7, Z=0.34, O R=1.68)$, type of presentation as CSA ( $\mathrm{p}=0.7, \mathrm{Z}=0.38, \mathrm{OR}=1.60,95 \% \mathrm{CI}=$ 0.14 to 17.7), presence of Left ventricular dysfunction $(\mathrm{p}=0.7, \mathrm{z}=0.38, \mathrm{OR}=1.60,95 \% \mathrm{CI}=0.14$ to 16.97$)$ and with pre-dilatation during $\operatorname{PCI}(\mathrm{p}=0.9, \quad \mathrm{z}=-0.16, \quad \mathrm{OR}=0.99)$ (Fig.2).These variables does not influence the procedural success but presence of total occlusion and significant tortuosity of LIMA will cause difficulties in wire crossing and stent negotiation to the anastamotic site.

\section{DISCUSSION}

The internal mammary artery grafts have an excellent record of success and long term patency, and with increasing usage of LIMA as the conduit in CABG, grafts have increased the incidence of stenosis in either the internal mammary artery (IMA) itself or the anastomosis site. The lower restenosis rate of IMA grafts, when compared to saphenous grafts, may be due to the resistance of the former to accelerated atherosclerosis [6]. Yang et al [7]. revealed that smooth muscle cells from the IMA have less pronounced growth activity in response to serum or platelet-derived growth factor-BB than vein grafts, despite normal PDGF receptor expression and function. Re-operation for patients with coronary artery disease incurs increased risk of morbidity, with a mortality rate as high as 5\% in experienced centers [8].Compared with native coronary
PCI, bypass graft PCI is independently associated with higher in-hospital mortality. Most of the bypass graft interventions in prior CABG patients were performed in SVGs (93\%), with much fewer (7\%) performed in arterial bypass grafts [9].Given the increased mortality and morbidity associated with repeat bypass surgery, PTCA to LIMA stenosis appears to be a viable alternative treatment. The majority of patients requiring intervention for LIMA graft problems have stenosis at the site of insertion into the native coronary artery, which can be treated by angioplasty with a high degree of procedural success. In a previous study by Ishizaka et al.[10] have reported that IMA grafts underwent PTCA mostly at the distal anastomosis (77\%-87\%).In our series, $81 \%$ of the procedures involved stenosis at the anastomosis sites. Several studies have described angioplasty of an IMA graft with reported success rates between $73 \%$ and $97 \%[11,12,13]$ similarly in our study the procedural success was $80.1 \%$. The $20 \%$ failure in the present study was caused by severe tortuosity of the IMA and diffuse degeneration of LIMA and total occlusion of the anastomosis site. A tortuous IMA increases trauma to the vessel wall, which can result in dissection during the wiring procedure. Slow coronary flow occurred in 5 patients and all of them regained TIMI III flow with intracoronary nitroglycerine which suggests that transient spasm of the LIMA. In our study, all the patients underwent the procedure through the right femoral artery even though high success and low complication rates have been demonstrated in transradial LIMA graft angiography and PTCA $[14,15,16]$. It was unclear whether the drug eluting stents offer superior long term results when compared to the Bare metal stents [17] in our study we used DES in the majority of patients. On binary logistic regression, there was no significant difference between successful PCI to the failed PCI with respect to age, sex, type of presentation, the presence of Left ventricular dysfunction and with pre-dilatation during PCI.

In conclusion, in the present 21 patients studied, the PTCA to LIMA graft appears to be a safe, feasible and beneficial procedure, with success achieved in $80 \%$ procedures. The presence of total or subtotal occlusion and vessel tortuosity are predictors of angioplasty failure and vessel dissection. Age, sex, clinical presentation and left ventricular dysfunction does not influence the procedural success. Limitations of this 
study included a small number of patients, different operators, retrospective registry based study and not a randomized study.

\section{REFERENCES:}

1. Loop FD, Lytle BW, Cosgrove DM, et al. Influence of the internal-mammary-artery graft on 10-year survival and other cardiac events. N Engl J Med 1986;314:1- 6 .

2.Sabik JF $3^{\text {rd, }}$ Lytle BW, Blackstone EH et al; Comparison of saphenous vein and internal thoracic artery graft patency by coronary system. Ann Thorac Surg. 2005 Feb;79(2):544-51.

3. Shimizu T, Hirayama T, Suesada H; et al. Effect of flow competition on internal thoracic artery graft: postoperative velocimetric and angiographic study. J Thorac Cardiovasc Surg 2000;120: 459 - 65.

4. Hearne SE, Davidson CJ, Zidar JP;et al. Internal mammary artery graft angioplasty: acute and long-term outcome. Cathet Cardiovasc Diagn 1998;44:153-6.

5.Gruberg L, Dangas G, Mehran R;et al. Percutaneous revascularization of the internal mammary artery graft: short- and long-term outcomes. J Am Coll Cardiol 2000;35:944-8.

6. Klein LW. Balloon angioplasty of internal mammary artery bypass grafts: bailing out the surgeons. Cathet Cardiovasc Diagn 1998;44:157-8.

7. Yang Z, Oemar BS, Carrel T; et al. Different proliferative properties of smooth muscle cells of human arterial and venous bypass vessels: role of PDGF receptors, mitogen-activated protein kinase, and cyclindependent kinase inhibitors. Circulation 1998;97:181-7.

8. Lytle BW, Loop FD, Cosgrove DM; et al Fifteen hundred coronary reoperations. Results and determinants of early and late survival. J Thorac Cardiovasc Surg 1987;93:847-59.

9.Brilakis ES, Rao SV, Banerjee S, et al. Percutaneous coronary intervention in native arteries versus bypass grafts in prior coronary artery bypass grafting patients: a report from the National Cardiovascular Data Registry. JACC Cardiovasc Interv. 2011;4:844-850

10. Ishizaka N, Ishizaka Y, Ikari Y;et al.. Initial and subsequent angiographic outcome of percutaneous transluminal angioplasty performed on internal mammary artery grafts. Br Heart J 1995;74: 615-9.

11. Popma JJ, Cooke RH, Leon MB; et al. Immediate procedural and long-term results of internal mammary artery angioplasty. Am J Cardiol 1992;69: 1237-9.

12. Dimas AP, Arora RR, Whitlow PL;et al. Percutaneous transluminal angioplasty involving internal mammary artery grafts. Am Heart J 1991;122: 423-9.

13. Sketch MH Jr, Quigley PJ, Perez JA;et al. Angiographic follow-up after internal mammary artery graft angioplasty. Am J Cardiol 1992;70: 401-3.

14. Mann T, Cubeddu G, Schneider J, Arrowood M. Left internal mammary artery intervention: the left radial approach with a new guide catheter. J Invasive Cardiol 2000;12:298-302.

15. Hung WC, Guo BF, Wu CJ, Chen CJ, Fang CY. Direct stenting of a transradial left internal mammary artery graft. Chang Gung Med J 2003;26:925-9.

16.Sharma S, Makkar RM. Percutaneous intervention on the LIMA: tackling the tortuosity. J Invasive Cardio 1 2003;15:359-62.

17. Xavier Freixa, Mahendra Carpen, , Mark A. Kotowycz.et al. Long-term Outcomes After Percutaneous Intervention of the Internal Thoracic Artery Anastomosis: The Use of Drug-Eluting Stents Is Associated With a Higher Need of Repeat Revascularization :Canadian Journal of Cardiology, Volume 28, Issue 4, July-August 2012, Pages 458-463 